\title{
Decreased Expression of ZNF554 in Gliomas is Associated with the Activation of Tumor Pathways and Shorter Patient Survival
}

\author{
Andrea Balogh ${ }^{1}$, Lilla Reiniger ${ }^{2}$, Szabolcs Hetey ${ }^{1}$, Peter Kiraly ${ }^{1}$, Eszter Toth ${ }^{1}$ (D), \\ Katalin Karaszi ${ }^{1,2}{ }^{\mathbb{D}}$, Kata Juhasz ${ }^{1}$, Zsolt Gelencser ${ }^{1}$, Agnes Zvara ${ }^{3}$, Andras Szilagyi ${ }^{1}{ }^{\mathbb{D}}$, \\ Laszlo G. Puskas ${ }^{3}$, Janos Matko ${ }^{4}$, Zoltan Papp ${ }^{5,6}$, Ilona Kovalszky ${ }^{2}$, Csaba Juhasz ${ }^{7,8}$ \\ and Nandor Gabor Than 1,2,5,* \\ 1 Systems Biology of Reproduction Research Group, Institute of Enzymology, Research Centre for \\ Natural Sciences, H-1117 Budapest, Hungary; balogh.andrea@ttk.hu (A.B.); heteysz@gmail.com (S.H.); \\ peter0kiraly@gmail.com (P.K.); toth.eszter@ttk.hu (E.T.); tika0604@gmail.com (K.K.); \\ ho12ember@gmail.com (K.J.); gelzsolt@gmail.com (Z.G.); szilagyi.andras@ttk.hu (A.S.) \\ 2 First Department of Pathology and Experimental Cancer Research, Semmelweis University, \\ H-1085 Budapest, Hungary; reiniger.lilla@med.semmelweis-univ.hu (L.R.); koval@korb1.sote.hu (I.K.) \\ 3 Laboratory of Functional Genomics, Department of Genetics, Biological Research Centre, \\ H-6726 Szeged, Hungary; zvara.agnes@gmail.com (A.Z.); laszlo@avidinbiotech.com (L.G.P.) \\ 4 Department of Immunology, Eotvos Lorand University, H-1117 Budapest, Hungary; matko@elte.hu \\ 5 Maternity Private Clinic, H-1126 Budapest, Hungary; pzorvosihetilap@maternity.hu \\ 6 Department of Obstetrics and Gynecology, Semmelweis University, H-1088 Budapest, Hungary \\ 7 Department of Pediatrics, Neurology, Neurosurgery, Wayne State University School of Medicine, \\ Detroit, MI 48201, USA; csaba.juhasz@wayne.edu \\ 8 Barbara Ann Karmanos Cancer Institute, Detroit, MI 48201, USA \\ * Correspondence: than.gabor@ttk.hu; Tel.: +36-1-382-6788
}

Received: 23 June 2020; Accepted: 5 August 2020; Published: 11 August 2020

Abstract: Zinc finger protein 554 (ZNF554), a member of the Krüppel-associated box domain zinc finger protein subfamily, is predominantly expressed in the brain and placenta in humans. Recently, we unveiled that ZNF554 regulates trophoblast invasion during placentation and its decreased expression leads to the early pathogenesis of preeclampsia. Since ZNF proteins are immensely implicated in the development of several tumors including malignant tumors of the brain, here we explored the pathological role of ZNF554 in gliomas. We examined the expression of ZNF554 at mRNA and protein levels in normal brain and gliomas, and then we searched for genome-wide transcriptomic changes in U87 glioblastoma cells transiently overexpressing ZNF554. Immunohistochemistry of brain tissues in our cohort $(n=62)$ and analysis of large TCGA RNA-Seq data $(n=687)$ of control, oligodendroglioma, and astrocytoma tissues both revealed decreased expression of ZNF554 towards higher glioma grades. Furthermore, low ZNF554 expression was associated with shorter survival of grade III and IV astrocytoma patients. Overexpression of ZNF554 in U87 cells resulted in differential expression, mostly downregulation of 899 genes. The "PI3K-Akt signaling pathway", known to be activated during glioma development, was the most impacted among 116 dysregulated pathways. Most affected pathways were cancer-related and/or immune-related. Congruently, cell proliferation was decreased and cell cycle was arrested in ZNF554-transfected glioma cells. These data collectively suggest that ZNF554 is a potential tumor suppressor and its decreased expression may lead to the loss of oncogene suppression, activation of tumor pathways, and shorter survival of patients with malignant glioma.

Keywords: glioma; glioblastoma; survival; transcriptome; zinc finger protein 


\section{Introduction}

Zinc-finger proteins (ZNFs) belong to one of the largest transcription factor families in the human genome showing a great diversity of molecular functions [1]. Notably, in addition to DNA binding, studies have recently revealed the RNA, protein, and lipid interacting abilities of zinc finger motifs [2-6]. Nearly one-third of ZNFs belong to the Krüppel-associated box domain zinc finger protein (KRAB-ZNF) subfamily and contribute to transcriptional regulation during various cellular processes including differentiation, cell growth, and morphogenesis [7-9]. The majority of KRAB-ZNFs are involved in epigenetic silencing mediated by the KAP1 co-repressor via the induction of histone H3K9 trimethylation and DNA methylation $[10,11]$.

ZNF554, a member of the KRAB-ZNF subfamily, is encoded in the KRAB-ZNF cluster on chromosome 19p13, which is highly coated by heterochromatin proteins and contains a large number of long interspersed nuclear elements (LINEs), denoting the tightly controlled regulation of its expression [12]. Surprisingly, our recent tissue qRT-PCR study revealed that ZNF554 gene expression is mostly restricted to the brain and placenta in humans [13]. Furthermore, our genome-wide transcriptomic analysis showed the emerging role of ZNF554 as a hub transcription factor that drives deep trophoblast invasion, and the pathogenesis of preeclampsia is partly originated from its dysregulation. As functional evidence, ZNF554-silenced extravillous trophoblast cells had reduced migratory and invasive functions [13].

The remarkable ZNF554 expression in the brain [13] was particularly interesting since ZNFs play a critical role in the development and differentiation of the nervous system. For instance, ZNF536 is abundant in the brain and is expressed in the developing central nervous system localized in the cerebral cortex, hippocampus, and hypothalamic area. ZNF536 expression is increased during cell differentiation and its overexpression inhibits retinoic-acid induced neuronal differentiation [14]. The importance of KRAB-ZNFs in the development and function of the brain is also supported by an interesting study, where differential expression of genes among human and chimpanzee tissues was compared. Nowick et al. found differential expression of 90 transcription factor genes only in the brain and revealed that they are organized in a co-expression network comprised of two modules, both enriched for primate-specific KRAB-ZNF genes [15].

Based on their essential role in transcription regulation, it is of major interest that many ZNF proteins act either as oncogenes or tumor suppressors [5,16], and are immensely implicated in the development of several tumors including gliomas [5]. Gliomas account for about $80 \%$ of all malignant primary brain tumors [17]. According to the most recent WHO classification criteria [18], most diffuse gliomas in adults belong to one of three molecular categories: Isocitrate dehydrogenase (IDH)-wildtype, IDH-mutant but 1p/19q-non-codeleted, or IDH-mutant and 1p/19q-codeleted. Histologically, 1p/19q-non-codeleted (IDH-wildtype or IDH-mutant) diffuse gliomas generally have an astrocytic phenotype, and the IDH-mutant and 1p/19q-codeleted tumors possess an oligodendroglial phenotype. Grade IV astrocytic glioma (glioblastoma multiforme (GBM)) is the most frequent adult glioma type and has the lowest survival rate [19]. Regarding the role of ZNFs in the development of gliomas, ZNF926 has been shown to promote cell proliferation and survival in gliomas [20], and stem cell maintenance in GBM [21]. In addition, Tatard et al. concluded in their study that antiproliferative functions of ZNF238 in normal granule neuron precursors and possibly other precursors counteract brain tumors (medulloblastoma and glioblastoma) formation [22].

Since ZNF554 is a regulator of cell invasion [13], and it has high expression in the brain, our collaborative teams $[13,23,24]$ hypothesized that it may play a role in glioma development. Accordingly, we aimed to examine the expression of ZNF554 both at RNA and protein levels in normal brain and adult diffuse gliomas, as well as the association of ZNF554 expression with patient survival, and to search for genome-wide transcriptomic and proteomic changes in glioblastoma cells transiently overexpressing ZNF554. To our knowledge, this is the first study that unveils the detailed expression pattern of ZNF554 in the human brain, the decreased expression of ZNF554 towards higher tumor grades, and ZNF554 as a favorable prognostic gene in adult diffuse gliomas. We also show that 
ZNF554 overexpression in U87 glioblastoma cells leads to dysregulation of several pathways and genes known to be impacted in adult diffuse gliomas. These results suggest that ZNF554 is a potential tumor suppressor and its decreased expression may lead to the activation of tumor pathways in adult diffuse gliomas, with a detrimental effect on patient survival.

\section{Results}

\subsection{Brain Tissue Expression Pattern of ZNF554}

Human tissue cDNA array expression profiling revealed that ZNF554 mRNA expression is the highest in the brain amongst 47 human adult tissues included in the analysis [13]. In addition, the second to fourth top tissues (spinal cord, optic nerve, retina), which have ca. 60\% lower ZNF554 expression level than the brain, also belong to the nervous system (Supplementary Figure S1A). When we took a closer look into the brain expression of ZNF554 using data from Allen Brain Atlas, and we found that ZNF554 expression shows low region specificity. Only the white matter, striatum, and the epithalamus had significantly lower $(p<0.05$ or $p<0.01)$ ZNF554 expression than other brain regions (Supplementary Figure S1B).

\subsection{ZNF554 Protein Expression in Gliomas}

Immunohistochemistry (IHC) results showed that ZNF554 protein expression decreased with increasing tumor grades in patients with oligodendroglioma (ODG) and astrocytoma (AC). In detail, average ZNF554 immunoscores were 33\% and 47\% lower in grade II and grade III ODG tumors, respectively, than in controls (control: $3.00 \pm 0.00$; ODG grade II: $2.00 \pm 0.26, p<0.05$; anaplastic ODG grade III: $1.60 \pm 0.22, p<0.001$, Figure 1A,B). In ACs, the average ZNF554 immunoscores were $40 \%$ and $52 \%$ lower in grade III and grade IV tumors, respectively, than in controls (control: $3.00 \pm 0.00$; anaplastic AC grade III: $1.80 \pm 0.29, p<0.05$; GBM grade IV: $1.45 \pm 0.25, p<0.01$, Figure $1 \mathrm{~A}, \mathrm{~B}$ ). The mean immunoscore for ZNF554 was lower in grade II AC tumors as well, although the difference did not reach statistical significance $(2.40 \pm 0.31$, Figure $1 \mathrm{~A}, \mathrm{~B})$.

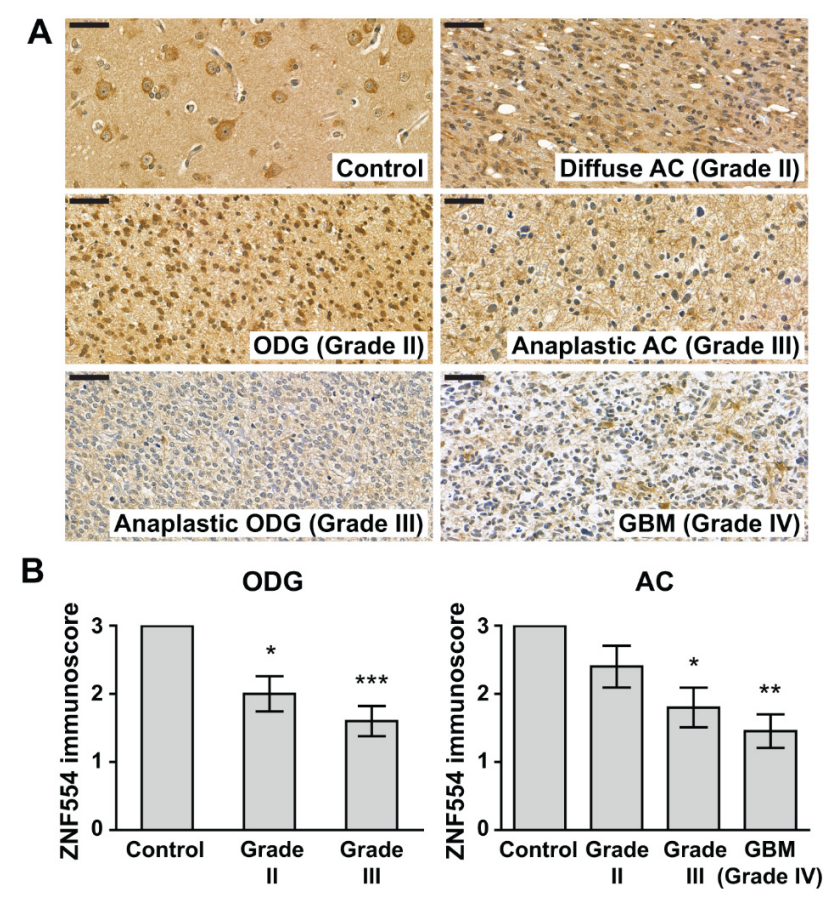

Figure 1. Zinc finger protein 554 (ZNF554) expression is decreased at the protein level in gliomas. (A) 5 - $\mu$ m-thick brain sections from controls $(n=11)$ and from patients with grade II $(n=10)$ or grade III $(n=10)$ oligodendroglioma, grade II $(n=10)$ or grade III $(n=10)$ astrocytoma, or glioblastoma $(n=11)$ 
were immunostained for ZNF554. ZNF554 protein abundance decreased with increasing tumor grades in patients with oligodendroglioma or with astrocytoma. Representative images, hematoxylin counterstain, $50 \mu \mathrm{m}$ scale bar, 400× magnifications. (B) ZNF554 immunoscores (mean \pm SEM) of patient groups are displayed on the left (control and oligodendrogliomas) and right (control and astrocytomas) graphs. Kruskal-Wallis with Dunn's post hoc test was used for the statistical analysis $\left({ }^{*} p<0.05\right.$, ** $\left.p<0.01,{ }^{* * *} p<0.001\right)$. Astrocytoma, AC; glioblastoma, GBM; oligodendroglioma, ODG.

\subsection{ZNF554 mRNA Expression in Gliomas}

Next, we aimed to confirm our findings at the mRNA level on larger cohorts. Therefore, we analyzed ZNF554 mRNA expression in gliomas from the TCGA database [25]. We found that the ZNF554 $\log _{2}$ expression level was lower in all glioma groups (ODG grade II: $7.673 \pm 0.027$, ODG grade III: $7.659 \pm 0.030$, AC grade II: $7.579 \pm 0.029$, AC grade III: $7.458 \pm 0.027$, GBM: $7.241 \pm 0.035, p<0.001$ in all cases) compared to controls (8.272 \pm 0.161 , Figure $2 A)$. Of note, there was no difference in ZNF554 expression in primary and recurrent gliomas Figure $2 B$ ). Furthermore, the survival probability of patients with high ZNF554 expression was higher than those with low ZNF554 expression when all gliomas were analyzed together $(p<0.001$, Figure $2 C)$. When gliomas were analyzed based on their type and grade, low ZNF554 expression associated with shorter survival of anaplastic AC (grade III, $p<0.05$ ) and GBM (grade IV, $p<0.05$ ) patients (including a subgroup of IDH-wildtype GBMs, $p<0.05$ ), but not with the survival of patients of the two ODG groups and the grade II AC group (Figure 2D-F).

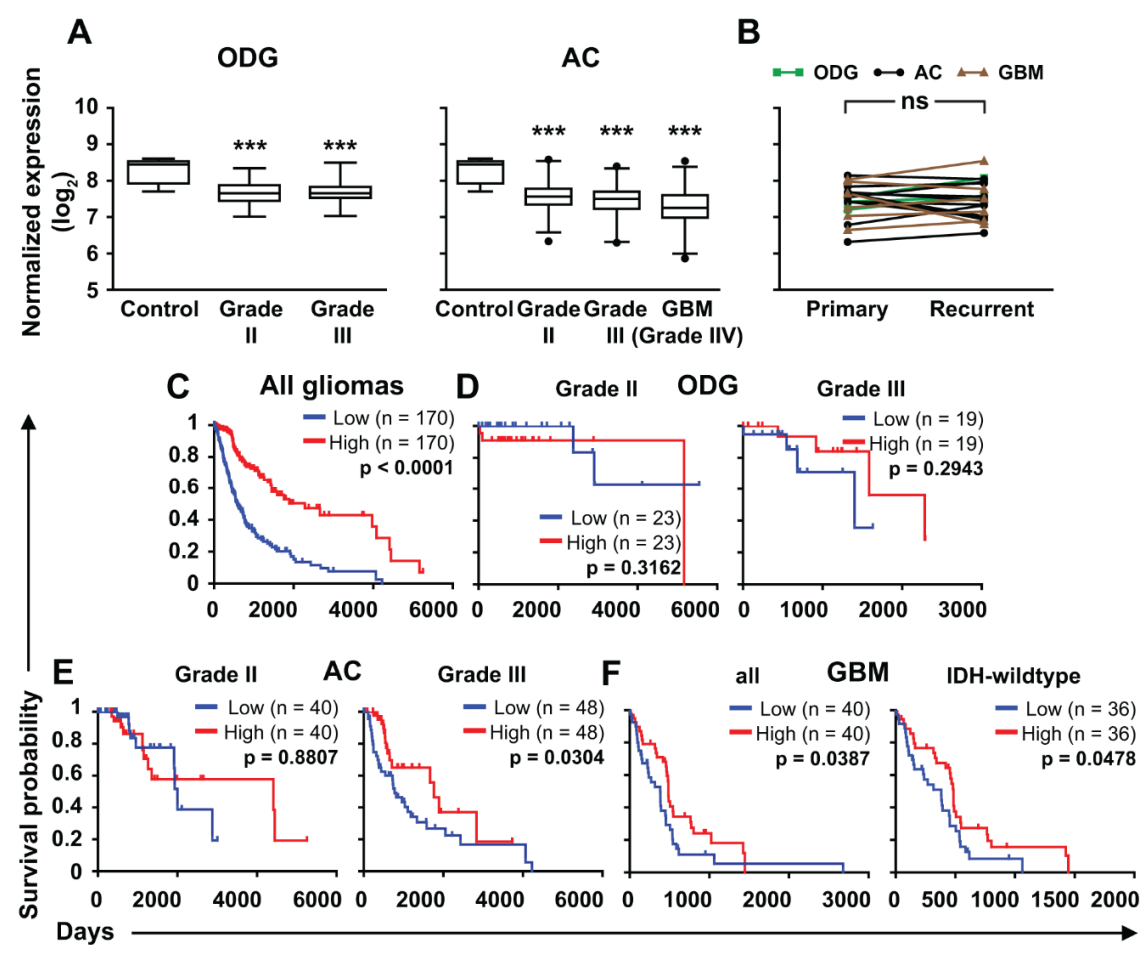

Figure 2. ZNF554 mRNA expression is decreased in gliomas and positively associates with patient survival. (A) Box plots (median and whiskers: 1-99 percentile) represent normalized gene expression levels ( $\log _{2}$ norm_count+1) of ZNF554 from processed control brain $(n=5)$, ODG (grade II, $n=93$; grade III, $n=75$, left graph), AC (grade II, $n=161$; grade III, $n=194$ ), and GBM (grade IV, $n=159$, right graph) RNA-Seq data from the TCGA database. One-way ANOVA with Dunnett's post hoc test $(* * * p<0.001)$ was used to compare glioma groups with the control group. (B) In 20 cases $\left(n_{\mathrm{ODG}}=3\right.$, $\left.n_{\mathrm{AC}}=11, n_{\mathrm{GBM}}=6\right)$, ZNF554 gene expression levels of primary and recurrent gliomas were compared by paired $t$-test and depicted on a before-after plot graph (ns: $p>0.05$ ). Outcome predictions of all gliomas ( $n=682, \mathrm{C})$, ODG (grade II, (D) left graph), anaplastic ODG (grade III, (D) right graph), diffuse AC (grade II, (E) left graph), anaplastic AC (grade III, (E) right graph), all (IDH-wildtype and IDH-mutant) GBM (grade IV, (F) left graph), and IDH-wildtype GBM (grade IV, (F) right graph) cases 
based on TCGA overall survival data were linked to ZNF554 mRNA expression level. Kaplan-Meier plots show survival correlations with high (red line) or low (blue line) expression levels of ZNF554. The lower and upper quartiles of patients were analyzed by the Log-rank (Mantel-Cox) test $(p<0.05$ was considered significant). Astrocytoma, AC; glioblastoma, GBM; isocitrate dehydrogenase, IDH; oligodendroglioma, ODG.

\subsection{The Effect of ZNF554 Overexpression in Glioblastoma Cells}

To reveal the impact of ZNF554 expression on glioblastoma cells, we transiently overexpressed ZNF554 in U87 glioblastoma cells. There was an average 92-fold increase in ZNF554 expression in transfected cells compared to cells transfected with the empty vector ${ }^{* *} p<0.01$, Figure $\left.3 \mathrm{~A}\right)$.

To further determine whether ZNF554 is a potential tumor suppressor in gliomas, the effect of ZNF554 on proliferation/viability and cell cycle of U87 cells was examined. After transient transfection with ZNF554, cell proliferation/viability decreased ( $p<0.05$, Figure 3B), and the number of U87 cells in the G0/G1 phase slightly but significantly increased from $46.65 \%$ to $48.05 \%$ ( $p<0.05$, Figure $3 C)$. These results suggested that cell proliferation inhibition by ZNF554 is likely mediated through cell cycle arrest at G0/G1.
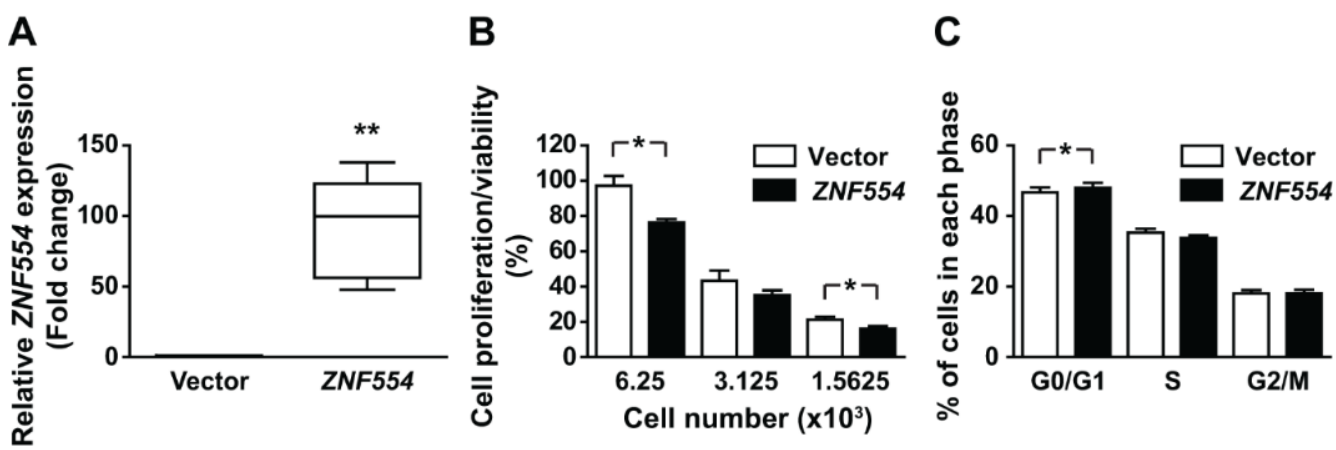

Figure 3. Overexpression of ZNF554 decreases cell proliferation and induces cell cycle arrest in U87 glioblastoma cells. (A) Box plots (median and whiskers: 1-99 percentile) represent the relative gene expression level of ZNF554 in U87 cells two days after transient transfection with pCMV-ZNF554 or empty vector. Quantitative RT-PCR data are from five independent experiments. Unpaired $t$-test with Welch correction was used for the statistical analysis ${ }^{* *} p<0.01$ ). (B) Analysis of cell proliferation/viability of vector- and ZNF554-transfected U87 cells by the Cell Counting Kit-8 assay. The percentage of cell proliferation relative to the vector-transfected control cells are presented as the mean \pm SEM. (C) Analysis of cell cycle distribution of vector- and ZNF554-transfected U87 cells by Hoechst33342 staining and flow cytometry. Percentage of cells (mean \pm SEM) in G0/G1, S, and G2/M phases are shown. Data were retrieved from three-four independent experiments. Paired $t$-test was used for the statistical analysis $\left({ }^{*} p<0.05\right)$.

Genome-scale gene expression analysis identified dysregulation of 4.77\% (899/18 834) of genes expressed in U87 glioblastoma cells overexpressing ZNF554 (Supplementary Table S1, Figure 4A). Of importance, the vast majority $(84 \%, 754 / 899)$ of these genes were downregulated, which is consistent with the overall repressive role of KRAB-ZNFs on gene transcription [8]. Among the top 20 upregulated genes were several cytokines (IL6, interleukin 6; IL18, IL36B) and chemokines (CCL20, C-C motif chemokine ligand 20; CCL5, CXCL2, C-X-C motif chemokine ligand 2), as well as $C D A$ (cytidine deaminase), CCDC134 (coiled-coil domain containing 134), and two HLA class II major histocompatibility antigens (HLA-DRB3, HLA-DRB5). Among the top 20 downregulated genes were a chemokine (CCL8), an integrin (ITGB1), two UDP-glucuronosyltransferases (UGT1A6, UGT1A8), transcripts for several proteins found in the endoplasmic reticulum (SERP1, stress associated endoplasmic reticulum protein 1; SEC23A, Sec23 homolog A, COPII coat complex component; TMED2, transmembrane p24 trafficking protein 2), a proto-oncogene (CASC4, cancer susceptibility 4) and 
IGFBP3 (insulin-like growth factor-binding protein 3). Of note, in the case of four genes selected for validation, there was a good correlation between microarray and qRT-PCR results (Figure 4B).



Figure 4. Genome-wide expression changes in U87 glioblastoma cells overexpressing ZNF554. (A) All 18,834 genes are represented in terms of their measured differences in abundance ( $x$-axis) and the significance of the difference ( $y$-axis) on a volcano plot. The significance is represented as a negative $\log$ (base 10) of the adjusted $p$-value so that more significant differences in expression are plotted higher on the $y$-axis. Dotted lines represent the thresholds used to select the probes for differentially expressed (DE) genes: $<-1$ and $>1$ for the magnitude of differential expression and pFDR of $<0.1$ for statistical significance. According to these criteria, of the $899 \mathrm{DE}$ genes, 145 were up-regulated (depicted with red), while 754 were down-regulated (depicted with dark green) in U87 cells transfected with ZNF554. (B) Correlation of microarray and qRT-PCR results for the selected genes (ETS1, IGFBP3, IL6, and ZNF554). The differences in the transcription of genes were $\log _{2}$-transformed and plotted against each other. Statistical results of Pearson's correlation are indicated $(p<0.05$ was considered significant). Two independent experiments in duplicates were performed. ETS proto-oncogene 1, ETS1; insulin-like growth factor binding protein 3, IGFBP3; interleukin 6, IL6; positive false-discovery rate, pFDR; zinc finger protein 554, ZNF554.

Analysis with iPathwayGuide to investigate biological processes and pathways dysregulated in U87 glioblastoma cells overexpressing ZNF554 revealed that the most impacted Kyoto Encyclopedia of Genes and Genomes (KEGG) pathways included "PI3K-Akt signaling" and "proteoglycans in cancer", both cancer-related pathways (Supplementary Table S2, Figures 5A and 6). Among the 116 dysregulated pathways, 73 were cancer-related, 86 were immune-related, and 49 pathways were common (Supplementary Table S2, Figure 5B). 

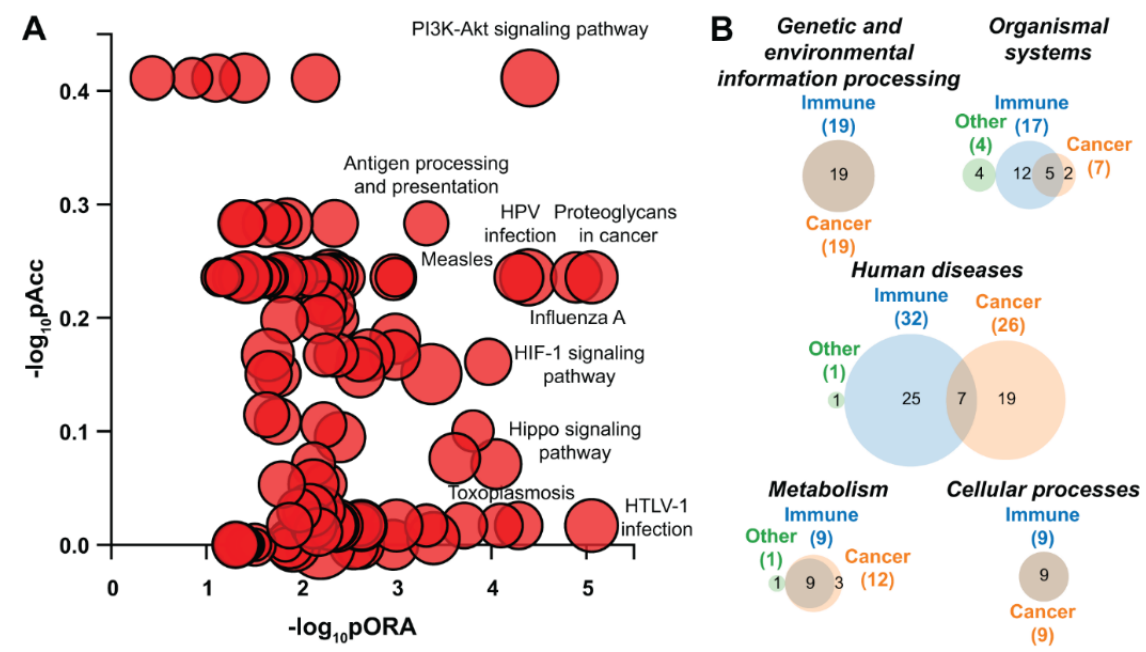

Figure 5. Pathways perturbation vs. over-representation and Venn diagrams in U87 glioblastoma cells overexpressing ZNF554. (A) Pathways (the 10 most dysregulated ones are indicated) were plotted according to two types of evidence computed by iPathwayGuide: Over-representation on the $x$-axis (pORA) and the total pathway accumulation on the $y$-axis (pAcc). For both, measured $p$-values are displayed on the negative log (base 10) scale. (B) Dysregulated pathways in U87 cells transfected with ZNF554 were categorized in five Kyoto Encyclopedia of Genes and Genomes (KEGG) pathway subgroups. Venn diagrams show the overlap between immune- and cancer-related biological pathways in these subgroups. Akt serine/threonine kinase, Akt; hypoxia-inducible factor 1-alpha, HIF-1; human papillomavirus, HPV; human T-cell leukemia virus 1, HTLV-1; phosphatidylinositol 3-kinase, PI3K.

A

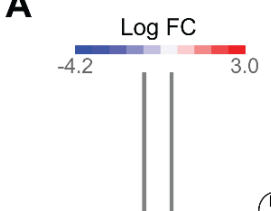

\section{PI3K-AKT SIGNALING PATHWAY}

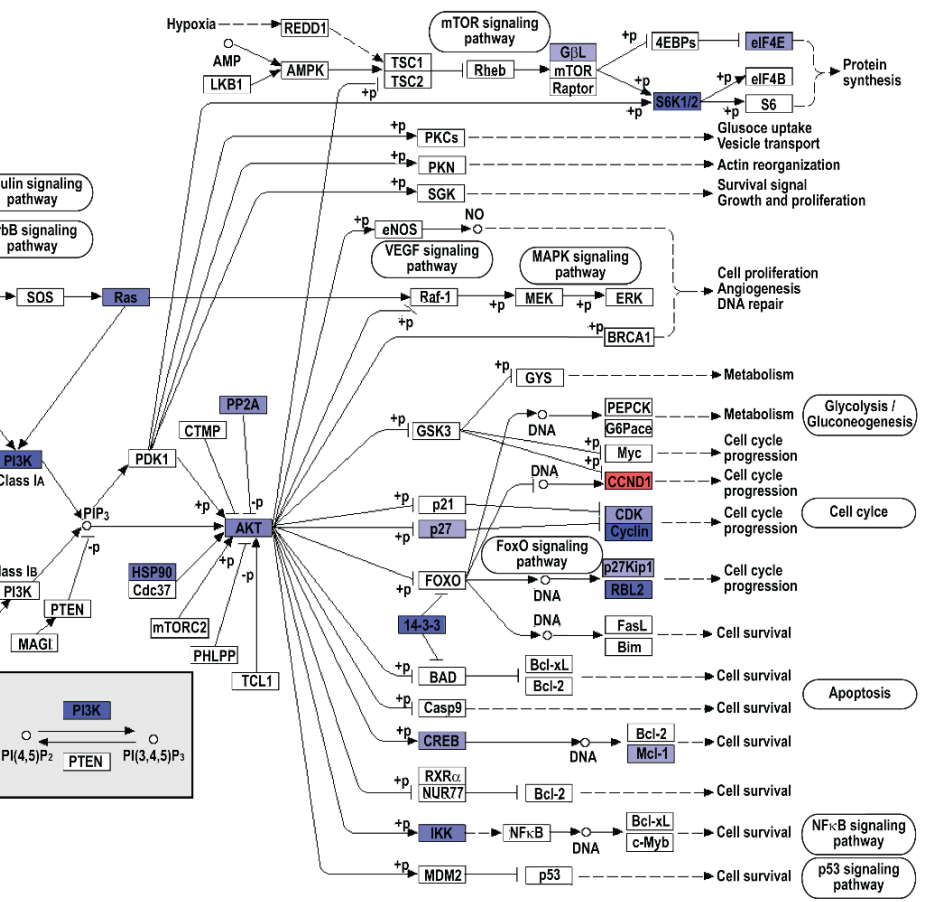

B

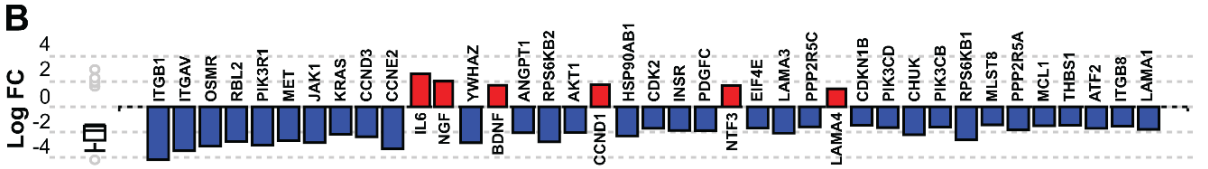

Figure 6. The PI3K-Akt signaling pathway is downregulated in U87 glioblastoma cells overexpressing ZNF554. (A) The Kyoto Encyclopedia of Genes and Genomes (KEGG) pathway diagram (KEGG: 04151) 
is overlaid with the computed log fold change of each gene. The downregulation is shown in dark blue, and the upregulation in dark red. The legend describes values on the gradient. (B) Gene log fold change bar plot. All genes in the PI3K-AKT signaling pathway were ranked according to log fold change, negative values were depicted in blue and positive values in red. The box and whisker plot on the left summarizes the distribution of all gene perturbations in this pathway, the box represents the first quartile, median and third quartile, while circles represent outliers. Akt serine/threonine kinase, Akt; phosphatidylinositol 3-kinase, PI3K.

Among 633 gene ontology (GO) biological processes dysregulated after positive false-discovery rate (pFDR) correction, the most impacted were "phosphorus metabolic process", "phosphate-containing compound metabolic process", "cellular response to chemical stimulus", and "vesicle-mediated transport" (Supplementary Table S3). We found the most impacted GO molecular functions to be "protein binding", "carbohydrate derivative binding", "anion binding", and "nucleotide binding" among 68 dysregulated molecular functions (Supplementary Table S4).

\section{Discussion}

\subsection{Principal Findings of This Study:}

(1) ZNF554 shows predominant brain expression with low region specificity in humans; (2) in adult diffuse gliomas, ZNF554 mRNA and protein expressions decrease with increasing tumor grade; (3) low ZNF554 mRNA expression is associated with shorter survival of anaplastic astrocytoma and glioblastoma patients, and also when all gliomas are analyzed together; (4) the overexpression of ZNF554 results in the dysregulation of 899 genes in U87 glioblastoma cells, and most of these are downregulated; (5) among 116 dysregulated pathways, 73 are cancer-related and 86 are immune-related (49 pathways are common), and these are mostly downregulated; and (6) the overexpression of ZNF554 decreases cell proliferation and induces cell cycle arrest.

\subsection{ZNFs in the Normal Human Brain}

The largest TF family in mammals is the family of KRAB-ZNF genes, and about one-third of these genes are primate-specific and evolved by recent gene duplications [26]. The rapid evolution of these genes in the human lineage is also demonstrated by the fact that there is an enrichment of KRAB-ZNF genes among DE genes in the human brain compared to chimpanzees [15]. Moreover, among the $\sim 350$ KRAB-ZNFs expressed in humans, a larger number of KRAB-ZNFs are expressed in the brain than in most other adult human tissues [9,27]. This evidence collectively suggests key roles of KRAB-ZNFs in brain development and the expansion of higher brain functions in humans. Of note, chromosome 19 contains the most KRAB-ZNF gene clusters, and ZNF554 is a member of the chr19p13.3 gene cluster [28]. Our results showed that ZNF554 has predominant brain expression among adult tissues with low region specificity. In a recent study, approximately 150 gene promoters were counted as binding sites for ZNF554 in the brain, and its expression is constant in space and time during neurodevelopment [29]. Besides ZNF554, Farmiloe et al. found that 50 other KRAB-ZNFs with more than 50 binding sites on gene promoter regions are expressed in the human brain, and these TFs can regulate gene expression in a region-specific manner during human brain development [29].

\subsection{ZNFs are Double-Edged Swords in Different Cancer Types}

We revealed decreased ZNF554 expression in adult diffuse gliomas with increasing tumor grade at both protein and mRNA levels, which possibly reflects its tumor suppressor nature in gliomas. Furthermore, lower ZNF554 expression was associated with worse prognosis in grade III ACs and GBMs. Those patients having the worst survival outcomes (IDH-wildtype GBM) showed longer overall survival with high ZNF554 expression. Interestingly, we found no apparent survival advantage of high ZNF554 expression for ODGs or low-grade ACs. The reason for these differences remains to be 
determined, but the lack of a significant survival effect for ODGs may be explained, at least partly, by the lower case numbers. Still, as Figure 2D demonstrates, high expressors in the Grade III ODG group actually lived longer than the low expressors, and this difference may well become significant in a larger cohort. For Grade II AC, the case numbers do not explain the lack of survival differences; although there were a few very long survivors ( $>10$ years) that were from the high expressor group.

ZNF671, also located on Chromosome 19, might play a tumor suppressor role in cancer since it was found downregulated in eight cancer-related ZNF671 single-cell RNA-Seq datasets. The heterogeneous functional states of cell subgroups and correlation analysis showed that ZNF671 played tumor suppressor roles in heterogeneous cancer cell populations. Western blot and transwell assays identified that ZNF671 inhibited epithelial-mesenchymal transition, migration, and invasion of central nervous system cancers, lung cancer, melanoma, and breast carcinoma in vitro [30]. Interestingly, a recent analysis of TCGA GBM samples [31] revealed that only 1.5\% (3/201) of genes associated with unfavorable prognosis in GBM are ZNF genes, while $18 \%(12 / 67)$ of genes associated with favorable prognosis in GBM are ZNF genes. However, (KRAB-)ZNFs may be double-edged swords since they could act as both tumor suppressors or oncogenes $[5,32,33]$. Even one ZNF can play different roles in different cancer types and upon various stimuli. For example, ZNF395 expression is induced under hypoxic stress in GBM, where it up-regulates interferon-stimulated and cancer-related genes, promoting inflammation and cancer progression [34]. In contrast, the tumor suppressor role of ZNF395 was proven in liver cancer, since the overexpression of miR-525-3p downregulated ZNF395, which promoted cancer cell migration and invasion [35]. These studies collectively showed that ZNFs may play different roles in different cancer types.

\subsection{ZNF554 as a Potential Tumor Suppressor in Gliomas}

To functionally investigate the potential tumor suppressor role of ZNF554 in gliomas, we performed genome-wide expression profiling of U87 glioblastoma cells transiently overexpressing ZNF554 and found that ZNF554 overexpression induced the upregulation of 145 genes and the downregulation of 754 genes. Functional analysis of these DE genes demonstrated a close correlation with cancer- and immune-related pathways. The "PI3K-Akt signaling" was the most significantly enriched pathway, and genes involved in this process included AKT1, JAK1, KRAS, MET, and PIK3R1. The PI3K-Akt signaling pathway regulates various cellular processes such as cell cycle, apoptosis, and cytoskeletal rearrangement [36]. This pathway can be activated by various growth factors, cytokines, chemokines, hormones, extracellular matrix components, etc., through their respective receptors (e.g., RTKs, cytokine receptors, GPCRs, adhesion molecules). It is located upstream to other pathways involved in cancerogenesis (e.g., mTor, Ras, MAPK, FoxO, and insulin signaling pathways) [37-42] which were also dysregulated in ZNF554-transfected cells. The importance of the PI3K-Akt signaling pathway in glioma is proven by ongoing clinical trials in brain tumors targeting, amongst others, PI3K and Akt $[43,44]$. Furthermore, we found decreased proliferation and cell cycle arrest of ZNF554-transfected cells, which might be due to the downregulation of several cyclin-dependent kinases (CDK2, CDK9, CDK10, CDK13, CDK17), and five (CCNC, CCND3, CCNE2, CCNG1, CCNG2) out of six cyclin genes. This is in strong concordance with recent studies, one showing the anti-glioma effect of CDK inhibitors already in preclinical/clinical use [45], the other finding several CDKs and cyclin genes amongst top hub nodes in glioma network analysis [46].

Similar to our study, the enrichment of "allograft rejection", "systemic lupus erythematosus", "graft-versus-host disease", "type I diabetes mellitus", "antigen processing and presentation", and "autoimmune thyroid disease" immune-related pathways were also found by Wang et al. analyzing DE genes in glioblastoma [47]. It was suggested by others that enhanced HLA class II expression in tumor cells may have significance in tumor immunogenicity, probably through enhanced direct tumor cell killing [48]. In addition, downregulation of major HLA class I and II genes in migrating cells in vitro and in invading cells in vivo was found in a glioma study [49]. 


\subsection{Potential Diagnostic and Therapeutic Implications of ZNF554 in Gliomas}

Our results suggest that ZNF554 may be a novel prognostic biomarker for clinical patient management, especially in those with grade III and IV gliomas. Future studies should evaluate if low-grade gliomas lose ZNF554 as they undergo malignant transformation into high-grade gliomas. Our in vitro studies suggest that enhanced expression of ZNF554 in such high-grade gliomas has the potential to suppress tumor growth and invasiveness. Thus, the potential promotion of its expression by gene therapy to restore ZNF554's tumor suppressor effect may provide therapeutic advantages and improve patient outcomes in adult diffuse gliomas. Such an effect would be particularly impactful in patients with the worst prognosis and severe treatment resistance with the current therapeutic options, such as those with IDH-wildtype GBM, where higher ZNF554 expression appeared to be beneficial for survival. Delivery vectors such as viral vectors, liposomes, non-polymeric and polymeric nanoparticles have been used in gene therapy of GBM [50]. For example, a Phase I clinical trial started in 1999 for the treatment of recurrent malignant glioma with adenovirus-mediated p53 TF gene therapy [51]. However, later it was suggested to be effective as a supplementary therapy because of insufficient gene transfer, lack of bystander effect, and tolerance arising from genetic heterogeneity of glioma $[52,53]$. Nevertheless, TFs have great potential as targets in the individualized therapeutic approaches to cancer [54]. Moreover, a combination of various therapies, e.g., gene-and chemotherapy, gene-and immunotherapy may further improve the effectiveness of glioma treatment.

\subsection{Strengths and Limitations}

The strengths of our study are as follows: (1) Strict clinical definitions and homogenous patient groups; (2) the use of leading bioinformatics tools for microarray, gene ontology, and pathway analyses; and (3) the immunohistochemical evaluation of a clinically and histologically well-characterized human diffuse glioma collection.

Limitations of our study are as follows: (1) Due to the strict selection criteria, we could include a relatively modest number of cases into the analysis of survival data, especially in some of the glioma subgroups; (2) the number of samples was modest in the microarray and IHC experiments; nevertheless, microarray results are meaningful and fit well with what was known about glioma molecular development, while IHC results corroborate our findings on the large TCGA data set showing decreased expression of ZNF554 at the mRNA level as well; and (3) we could only use a glioblastoma cell line and not primary glioblastoma cells for the overexpression of ZNF554 since we had no tissue source for primary cells. While U87 cells used in our study are among the most commonly used glioma cell lines in neuro-oncology research, future studies could involve other glioma cell lines to test baseline expression of ZNF554 and its expression in overexpression/siRNA systems.

\section{Conclusions}

ZNF554 is a potential tumor suppressor, and its decreased expression may lead to the loss of oncogene suppression, activation of tumor pathways, and shorter survival in malignant glioma patients. Although in vitro experiments were performed on an astrocytic glioma cell line, TCGA ZNF554 mRNA expression data indicate the importance of ZNF554 in the pathophysiology of oligodendrogliomas as well. ZNF554 overexpression in U87 glioblastoma cells induced gene expression changes associated with cancer-and immune-related pathways, with the PI3K-Akt signaling pathway enriched most significantly. Further studies, including single-cell RNA-seq analysis (with deep sequencing) on normal and tumorous human brain, are required to understand the precise role of ZNF554 in brain functions and oligodendroglial as well as astrocytic glioma development, and to reveal its diagnostic and therapeutic potential in the prognostication and targeted therapy of adult diffuse glioma patients. 


\section{Materials and Methods}

\subsection{Analysis of ZNF554 mRNA Expression in Normal Brain}

Microarray data (Allen Human Brain Atlas data 2010 [55]) from six donors were downloaded from http://human.brain-map.org in $\log _{2}$ format. The 169 different brain regions were grouped in 23 structural regions and ZNF554 expression levels (probe set ID: A_23_P343250) were visualized on a bar chart.

\subsection{Analysis of ZNF554 Protein Expression in Gliomas}

Formalin-fixed paraffin-embedded (FFPE) brain biopsy specimens of 62 patients were studied from the archives of the First Department of Pathology and Experimental Cancer Research, Semmelweis University. Tumor tissues were classified according to the WHO classification of Tumors of the Central Nervous System [18]. Based on the presence/absence of histological features, diffuse gliomas, within oligodendroglial or astrocytic phenotype, are graded as WHO grade II (low-grade), WHO grade III (anaplastic), or WHO grade IV (glioblastoma), the latter two referred to as high-grade gliomas [56]. Permissions to use the archived tissues were obtained from the Local Ethics Committee (TUKEB Approval No.: 155/2012) and the study was conducted in accordance with the Declaration of Helsinki.

Fifty-one brain tumor tissues, including 10 cases of each diffuse astrocytoma (AC), anaplastic AC, oligodendroglioma (ODG), anaplastic ODG, as well as 11 cases of GBM were selected for the immunostaining. In addition, 11 samples of normal brain tissue, confirmed by histopathology, from patients who underwent surgery for epilepsy were used as controls. Clinical information for these patients is included in Table 1.

Table 1. Demographic and clinical characteristics of the immunohistochemistry study groups.

\begin{tabular}{ccccc}
\hline Groups & Grade & $\boldsymbol{n}^{\mathbf{a}}$ & Age (Years) at Diagnosis $^{\mathbf{a}}$ & Male/Female $^{\mathbf{b}}$ \\
\hline Control (epilepsy) & - & 11 & $38.0(14-64)$ & $5 / 6$ \\
\hline Oligodendroglioma & II & 10 & $51.5(29-65)$ & $3 / 7$ \\
\hline Anaplastic oligondendroglioma & III & 10 & $47.0(30-67)$ & $3 / 7$ \\
\hline Diffuse astrocytoma & II & 10 & $47.0(29-69)$ & $4 / 6$ \\
\hline Anaplastic astrocytoma & III & 10 & $41.5(31-78)$ & $6 / 4$ \\
\hline Glioblastoma multiforme & IV & 11 & $64.0(24-73)$ & $6 / 5$ \\
\hline${ }^{\text {a }}$ Values are presented as numbers. ${ }^{\mathbf{b}}$ Values are presented as median (interquartile (IQR) range).
\end{tabular}

\subsection{Immunohistochemistry for ZNF554}

Five-micrometer-thick tissue sections were cut and mounted on SuperFrost ${ }^{\mathrm{TM}}$ Plus slides (Thermo Fisher Scientific, Waltham, MA, USA) and stored at $4{ }^{\circ} \mathrm{C}$ until the staining. Immunostaining was carried out using the Novolink Polymer Detection System (Leica-Novocastra, Nussloch, Germany) according to the manufacturer's protocol. Slides were dewaxed using xylene and rehydrated in graded alcohol series. Endogenous peroxidases were blocked with $10 \% \mathrm{H}_{2} \mathrm{O}_{2}$ in methanol $(20 \mathrm{~min}$, room temperature). Antigen retrieval was performed at $37^{\circ} \mathrm{C}$ for $5 \mathrm{~min}$ using the Bond Enzyme Pretreatment Kit (Leica Biosystems). After blocking non-specific binding with the Novocastra Protein Block (10 min, room temperature), slides were incubated with mouse polyclonal anti-ZNF554 antibody (Abnova, Taipei, Taiwan) at 1:50 dilution overnight at $4{ }^{\circ} \mathrm{C}$. After post-primary amplification $(30 \mathrm{~min}$, room temperature), slides were incubated with the Novolink Polymer (30 $\mathrm{min}$, room temperature) and visualized with 3,3'-diaminobenzidine (DAB) for $10 \mathrm{~min}$. Finally, sections were counterstained with hematoxylin, and these were mounted (DPX Mountant; Sigma-Aldrich, St. Louis, MO, USA) after dehydration. The primary antibody was omitted in negative controls. 


\subsection{Evaluation of ZNF554 Immunostainings}

Visual evaluation of ZNF554 immunostainings was performed microscopically (Carl Zeiss Microscopy $\mathrm{GmbH}$, Jena, Germany) by a pathologist (LR) blinded to the clinical data. The intensity of the staining was recorded as absent, weak, moderate, or strong. The percentage of positive tumor cells was scaled as follows: (i) Less than $10 \%$, (ii) $10-50 \%$, and (iii) more than $50 \%$ positive tumor cells. ZNF554 protein expression was defined negative/weak (score 1) if less than $10 \%$ of the cells showed any positivity; medium (score 2) if $10-50 \%$ of the cells showed any positivity or more than $50 \%$ of the cells showed weak/moderate positivity; and high (score 3) if more than $50 \%$ of the cells showed strong positivity.

\subsection{Analysis of ZNF554 mRNA Expression and Patients' Survival in Gliomas}

Based on The Cancer Genome Atlas (TCGA) Lower-Grade Glioma and Glioblastoma Multiforme study [57], normal brain, ODG (grades II and III), AC (grades II and III), and GBM (grade IV) ZNF554 RNA-Seq data were downloaded from the UCSC Xena platform [58] (https://xenabrowser.net/) in $\log _{2}$ normalized form ( $\log _{2}$ norm_count+1). Data were filtered for patients with known ZNF554 expression and survival data. Patients were reclassified according to the latest WHO glioma classification criteria [18], based on molecular data. Finally, 687 patients (Supplementary Table S5) were included in the analysis: normal brain $(n=5)$, ODG (grade II, $n=93$ ), anaplastic ODG (grade III, $n=75$ ), diffuse AC (grade II, $n=161$ ), anaplastic AC (grade III, $n=194$ ), and GBM (grade IV, $n=159)$. ZNF554 expression levels in different patient groups or primary and recurrent glioma cases $(n=20)$ were visualized on box plots and before-after plots, respectively, using the GraphPad Prism 5 software.

Outcome predictions of all gliomas together, as well as grade II ODG, grade III ODG, grade II AC, grade III AC, and grade IV GBM cases based on TCGA survival data linked to ZNF554 mRNA expression level, were visualized on Kaplan-Meier plots with high or low. In the analysis, patients with ZNF554 expression in the lower and upper quartiles were included.

\subsection{Transient Transfection of U87 Glioblastoma Cells with ZNF554}

Human U87 glioblastoma cells, obtained from the American Type Culture Collection (ATCC, Manassas, VI, USA), were cultured in Dulbecco's modified Eagle's medium (DMEM; Gibco-Thermo Fisher Scientific) supplemented with $10 \%$ fetal bovine serum (FBS; Gibco-Thermo Fisher) at $37{ }^{\circ} \mathrm{C}$ in a humidified $95 \%$ air and $5 \% \mathrm{CO}_{2}$ atmosphere. Cells were transfected with expression plasmid pCMV6-ZNF554 (OriGene, Rockville, MD, USA) or empty vector pCMV6 (OriGene) using Lipofectamine-2000 (Thermo Fisher Scientific) following the manufacturer's instructions. Transfection media was replaced with fresh medium six hours post-transfection. Cells were split into two batches $24 \mathrm{~h}$ after transfection, harvested $48 \mathrm{~h}$ after transfection, washed twice with ice-cold Dulbecco's PBS, and then pellets were stored at $-80^{\circ} \mathrm{C}$ until use.

\subsection{Total RNA Isolation}

Total RNA was isolated from U87 cells by the Direct-zol ${ }^{\mathrm{TM}}$ RNA MiniPrep kit (Zymo Research, Irvine, CA, USA) according to the manufacturers' protocols. RNA concentrations were measured on a NanoDrop ND-1000 Spectrophotometer (Thermo Fisher Scientific). RNA integrity and quality were assessed on a Bioanalyzer 2100 (Agilent Technologies, Santa Clara, CA, USA). Isolated RNA was stored at $-80^{\circ} \mathrm{C}$ until use.

\subsection{Labeling and Microarray Hybridization}

One microgram of total RNA was first reverse transcribed in $10 \mu \mathrm{L}$ volume using Oligo(dT) Primer and ArrayScript ${ }^{\mathrm{TM}}$ enzyme (Thermo Fisher Scientific), then the second cDNA strand was synthesized in $50 \mu \mathrm{L}$ final volume using DNA Polymerase and RNase H (Thermo Fisher Scientific). Amino allyl-modified antisense RNA (aaRNA) was then synthesized by in vitro transcription using 
amino allyl-modified UTP and T7 Enzyme mix. All these steps were done using the Amino Allyl MessageAmp ${ }^{\mathrm{TM}}$ II aRNA Amplification Kit (Ambion-Thermo Fisher Scientific), according to the manufacturer's instructions. Six $\mu \mathrm{g}$ of amino allyl-modified amplified RNA was labeled with Cy3 dye in $10 \mu \mathrm{L}$ volume according to the manufacturer's instructions (One-Color Quick Amp Labeling Kit, Agilent Technologies) and purified with RNeasy Mini Kit (Qiagen). The incorporation rate of the dye and the labeled aaRNA concentration were detected using NanoDrop 3.1.0. The incorporation rate of the samples was 30-60 dye molecules per 1000 nucleotides.

The human oligonucleotide microarray (Whole Human Genome Microarray, $4 \times 44 \mathrm{~K}$, G2519F, Design ID 014850, Agilent Technologies) was used to determine gene expression changes. $825 \mathrm{ng}$ of Cy3 labeled aaRNA, $11 \mu \mathrm{L}$ 10X Blocking Agent and $2.2 \mu \mathrm{L}$ 25X Fragmentation Buffer were mixed in a final volume of $55 \mu \mathrm{L}$ and fragmented at $60^{\circ} \mathrm{C}$ for $30 \mathrm{~min}$ then $55 \mu \mathrm{L} 2 \mathrm{X}$ GEx Hybridization Buffer were added to each sample to stop the fragmentation reaction. All these steps were done using the Gene Expression Hybridization Kit of Agilent Technologies according to the manufacturer's instructions. A hundred microliters of these mixes were used to fill the 4-plex backing slides and the microarray was placed onto it. This "hybridization sandwich" was assembled in an Agilent microarray hybridization chambers. The chambers were then loaded into a hybridization rotator rack $(\sim 5 \mathrm{rpm})$ and incubated at $65^{\circ} \mathrm{C}$ for $17 \mathrm{~h}$. After hybridization, the slides were washed in Wash buffer 1 at room temperature for $1 \mathrm{~min}$ then in Wash buffer 2 at $37^{\circ} \mathrm{C}$ for another $1 \mathrm{~min}$ before scanning. Each array was scanned at $543 \mathrm{~nm}$ (for Cy3 labeling) in an Agilent Scanner (G2505B) using the extended dynamic range function with $5 \mu \mathrm{m}$ resolution. Output image analysis and feature extraction were done using Feature Extraction 9.5.1 software using the single-color gene expression protocol (GE1_1100_Jul11) [59].

\subsection{Quantitative Real-Time PCR}

Five hundred nanograms of total RNA was transcribed by the qScript cDNA Synthesis kit (Quantabio, Beverly, MA, USA). TaqMan ${ }^{\text {TM }}$ Gene Expression Assays (Table 2) and Universal PCR Master Mix (Applied Biosystems-Thermo Fisher Scientific) were used for gene expression quantification on a Biomark system (Fluidigm, San Francisco, CA, USA). Ct values for each target gene (ETS1, IGFBP3, $I L 6$, and ZNF554) and the endogenous control (RPLPO) were averaged over three technical replicates. For each target gene, the fold change was calculated using the delta-delta $\mathrm{Ct}$ method. In the correlation analysis, fold change data were $\log _{2}$ transformed.

Table 2. TaqMan assays used for qRT-PCR expression profiling.

\begin{tabular}{ccc}
\hline Gene Symbol & Gene Name & Assay ID \\
\hline ZNF554 & Zinc finger protein 554 & Hs00171072_m1 \\
\hline IL6 & Interleukin 6 & Hs00174131_m1 \\
\hline IGFBP3 & Insulin-like growth factor-binding protein 3 & Hs00181211_m1 \\
\hline RPLP0 & Ribosomal protein lateral stalk subunit P0 & Hs99999902_m1 \\
\hline
\end{tabular}

\subsection{Proliferation/Viability Assay}

Forty-eight hours after transfection, the Cell Counting Kit-8 (Merck-Sigma Aldrich) colorimetric assay was used to measure cell proliferation, according to the manufacturer's instruction. The mean optical density (OD at $450 \mathrm{~nm}$ ) of three wells for the groups was used to calculate the percentage of cell proliferation relative to the vector-transfected control cells.

\subsection{Cell Cycle Assay}

Forty-eight hours after transfection, $2.5 \mu \mathrm{g} / \mathrm{mL}$ Hoechst33342 (Thermo Fisher Scientific) was added to the cells. Samples were incubated at $37^{\circ} \mathrm{C}$ for $1 \mathrm{~h}$ then were trypsinized and measured on a Cytoflex instrument (Beckman Coulter, Brea, CA, USA). Twenty thousand events were collected per sample. 
Late apoptotic/necrotic cells, stained by propidium iodide (Merck-Sigma Aldrich), were excluded from the analysis.

\subsection{Data Analysis}

\subsubsection{Allen Brain Atlas Data Analysis}

Downloaded ZNF554 mRNA expression data were averaged to larger brain regions and statistical analysis was performed by Kruskal-Wallis with Dunn's post hoc test to compare the groups. $p$-values of $<0.05$ were considered significant.

\subsubsection{TCGA RNA-Seq Data Analysis}

Downloaded data were filtered for ZNF554 expression in the normal brain and glioma tissues. Mixed gliomas were excluded from the analysis. One-way ANOVA with Dunnett's post hoc test was used to compare glioma groups with the control group for ZNF554 expression. The paired $t$-test was used to compare ZNF554 expression in primary and recurrent gliomas. The Log-rank (Mantel-Cox) test was used for survival analysis. $p$-values of $<0.05$ were considered significant.

\subsubsection{Microarray Data Analysis of Transfected U87 Cells}

For U87 cells overexpressing ZNF554, analyses were performed in $R$ statistical environment using the limma package of Bioconductor (www.bioconductor.org). Following quality control performed by arrayQualityMetrics [60], expression data were background corrected with the normexp method and quantile normalized. Prior to differential gene expression analysis, irregular replicate probes were averaged with avereps function of the limma package. Genes were selected as differentially expressed upon a False Discovery Rate (FDR) [61] adjusted $p$-value of $<0.1$ and fold-change of $\geq 2$. The hgug4112a.db Agilent whole-genome database was used for gene annotation.

\subsubsection{Pathway Analysis}

To identify significantly impacted pathways, biological processes, and molecular functions, we compared gene expression between U87 cells transfected with an empty vector or with ZNF554 using Advaita Bio's iPathwayGuide (https://www.advaitabio.com/ipathwayguide). This software analysis tool implements the 'Impact Analysis' approach that takes into consideration the direction and type of all signals on a pathway, the position, role, and type of every gene [62].

\subsubsection{Quantitative RT-PCR Data Analysis}

Unpaired $t$-test with Welch correction was used to compare the relative expression of ZNF554 between cells transfected with pCMV-ZNF554 vs. empty vector from five independent experiments. Pearson's correlation analysis was used to calculate the correlation strength and direction between microarray and qRT-PCR data for the selected genes from two independent experiments. $p$-values of $<0.05$ were considered significant.

\subsubsection{Data Analysis of ZNF554 Immunostainings}

Kruskal-Wallis with Dunn's post hoc test was used to compare mean immunoscores between control and patient groups. $p$-values of $<0.05$ were considered significant.

\subsubsection{Data Analysis of Cell Proliferation/Viability and Cell Cycle}

The paired $t$-test was used to compare proliferation (background-corrected optical density at $450 \mathrm{~nm}$ ) or cell cycle status (percent of cells in G0/G1, S, and G2/M phases) of cells transfected with pCMV-ZNF554 or empty vector from three-four independent experiments. $p$-values of $<0.05$ were considered significant. 
Supplementary Materials: The following are available online at http://www.mdpi.com/1422-0067/21/16/5762/s1.

Author Contributions: Conceptualization, A.B., L.R. and N.G.T.; formal analysis, A.B., L.R., S.H., P.K., E.T., Z.G., A.S., J.M., C.J. and N.G.T.; funding acquisition, A.B., A.S. and N.G.T.; investigation, A.B., L.R., S.H., K.K., K.J. and A.Z.; methodology, A.B., L.R. and N.G.T.; project administration, N.G.T.; resources, L.R., L.G.P., I.K. and N.G.T., supervision, N.G.T.; validation, A.B., L.R., E.T., A.S., Z.P. and N.G.T.; visualization, A.B., L.R., S.H., P.K. and N.G.T.; writing-original draft, A.B., L.R., S.H., P.K., E.T., A.Z., L.G.P., C.J. and N.G.T.; writing-review and editing. All authors have read and agreed to the published version of the manuscript.

Funding: This research was supported by the Hungarian Scientific Research Fund (K128262 grant to A.Sz. and K124862 grant to N.G.T.); Hungarian Academy of Sciences (Momentum LP2014-7/2014 grant to N.G.T., Premium_2019-436 grant to B.A., Young Research Fellowships to Sz.H. and E.T.), and Hungarian National Research, Development, and Innovation Office (FIEK_16-1-2016-0005 grant and VEKOP-2.3.3-15-2017-0014 grant to N.G.T.).

Acknowledgments: We thank Judit Baunoch, Judit Kapitany, and Orsolya Oravecz (Research Centre for Natural Sciences) for their assistance.

Conflicts of Interest: The authors declare no conflict of interest.

\section{References}

1. Cassandri, M.; Smirnov, A.; Novelli, F.; Pitolli, C.; Agostini, M.; Malewicz, M.; Melino, G.; Raschella, G. Zinc-finger proteins in health and disease. Cell Death Discov. 2017, 3, 1-12. [CrossRef] [PubMed]

2. Brayer, K.J.; Kulshreshtha, S.; Segal, D.J. The protein-binding potential of $\mathrm{C}_{2} \mathrm{H}_{2}$ zinc finger domains. Cell Biochem. Biophys. 2008, 51, 9-19. [CrossRef] [PubMed]

3. Font, J.; Mackay, J.P. Beyond DNA: Zinc finger domains as RNA-binding modules. In Engineered Zinc Finger Proteins; Font, J., Mackay, J.P., Eds.; Humana Press: Totowa, NJ, USA, 2010; Volume 649, pp. 479-491.

4. Planel, S.; Salomon, A.; Jalinot, P.; Feige, J.J.; Cherradi, N. A novel concept in antiangiogenic and antitumoral therapy: Multitarget destabilization of short-lived mRNAs by the zinc finger protein ZFP36L1. Oncogene 2010, 29, 5989-6003. [CrossRef] [PubMed]

5. Jen, J.; Wang, Y.C. Zinc finger proteins in cancer progression. J. Biomed. Sci. 2016, 23, 53. [CrossRef] [PubMed]

6. Nicolai, S.; Mahen, R.; Raschella, G.; Marini, A.; Pieraccioli, M.; Malewicz, M.; Venkitaraman, A.R.; Melino, G. ZNF281 is recruited on DNA breaks to facilitate DNA repair by non-homologous end joining. Oncogene 2020, 39, 754-766. [CrossRef] [PubMed]

7. Rowe, H.M.; Jakobsson, J.; Mesnard, D.; Rougemont, J.; Reynard, S.; Aktas, T.; Maillard, P.V.; Layard-Liesching, H.; Verp, S.; Marquis, J.; et al. KAP1 controls endogenous retroviruses in embryonic stem cells. Nature 2010, 463, 237-240. [CrossRef]

8. Lupo, A.; Cesaro, E.; Montano, G.; Zurlo, D.; Izzo, P.; Costanzo, P. KRAB-Zinc Finger Proteins: A Repressor Family Displaying Multiple Biological Functions. Curr. Genom. 2013, 14, 268-278. [CrossRef]

9. Ecco, G.; Imbeault, M.; Trono, D. KRAB zinc finger proteins. Development 2017, 144, 2719-2729. [CrossRef]

10. O'Geen, H.; Squazzo, S.L.; Iyengar, S.; Blahnik, K.; Rinn, J.L.; Chang, H.Y.; Green, R.; Farnham, P.J. Genome-wide analysis of KAP1 binding suggests autoregulation of KRAB-ZNFs. PLoS Genet. 2007, 3, e89. [CrossRef]

11. Oleksiewicz, U.; Gladych, M.; Raman, A.T.; Heyn, H.; Mereu, E.; Chlebanowska, P.; Andrzejewska, A.; Sozanska, B.; Samant, N.; Fak, K.; et al. TRIM28 and Interacting KRAB-ZNFs Control Self-Renewal of Human Pluripotent Stem Cells through Epigenetic Repression of Pro-differentiation Genes. Stem Cell Rep. 2017, 9, 2065-2080. [CrossRef]

12. Vogel, M.J.; Guelen, L.; de Wit, E.; Peric-Hupkes, D.; Loden, M.; Talhout, W.; Feenstra, M.; Abbas, B.; Classen, A.K.; van Steensel, B. Human heterochromatin proteins form large domains containing KRAB-ZNF genes. Genome Res. 2006, 16, 1493-1504. [CrossRef] [PubMed]

13. Than, N.G.; Romero, R.; Tarca, A.L.; Kekesi, K.A.; Xu, Y.; Xu, Z.; Juhasz, K.; Bhatti, G.; Leavitt, R.J.; Gelencser, Z.; et al. Integrated Systems Biology Approach Identifies Novel Maternal and Placental Pathways of Preeclampsia. Front. Immunol. 2018, 9, 1661. [CrossRef] [PubMed]

14. Qin, Z.; Ren, F.; Xu, X.; Ren, Y.; Li, H.; Wang, Y.; Zhai, Y.; Chang, Z. ZNF536, a novel zinc finger protein specifically expressed in the brain, negatively regulates neuron differentiation by repressing retinoic acid-induced gene transcription. Mol. Cell Biol. 2009, 29, 3633-3643. [CrossRef] [PubMed] 
15. Nowick, K.; Gernat, T.; Almaas, E.; Stubbs, L. Differences in human and chimpanzee gene expression patterns define an evolving network of transcription factors in brain. Proc. Natl. Acad. Sci. USA 2009, 106, 22358-22363. [CrossRef]

16. Kim, S.H.; Kim, E.J.; Hitomi, M.; Oh, S.Y.; Jin, X.; Jeon, H.M.; Beck, S.; Jin, X.; Kim, J.K.; Park, C.G.; et al. The LIM-only transcription factor LMO2 determines tumorigenic and angiogenic traits in glioma stem cells. Cell Death Differ. 2015, 22, 1517-1525. [CrossRef]

17. Schwartzbaum, J.A.; Fisher, J.L.; Aldape, K.D.; Wrensch, M. Epidemiology and molecular pathology of glioma. Nat. Clin. Pract. Neurol. 2006, 2, 494-503. [CrossRef]

18. Louis, D.N.; Ohgaki, H.; Wiestler, O.D.; Cavenee, W.K. WHO Classification of Tumours of the Central Nervous System, Revised, 4th ed.; IARC Press: Lyon, France, 2016; p. 408.

19. Gittleman, H.; Boscia, A.; Ostrom, Q.T.; Truitt, G.; Fritz, Y.; Kruchko, C.; Barnholtz-Sloan, J.S. Survivorship in adults with malignant brain and other central nervous system tumor from 2000-2014. Neuro Oncol. 2018, 20, vii6-vii16. [CrossRef]

20. Zhu, Z.; Li, K.; Xu, D.; Liu, Y.; Tang, H.; Xie, Q.; Xie, L.; Liu, J.; Wang, H.; Gong, Y.; et al. ZFX regulates glioma cell proliferation and survival In Vitro and In Vivo. J. Neuro Oncol. 2013, 112, 17-25. [CrossRef]

21. Fang, X.; Huang, Z.; Zhou, W.; Wu, Q.; Sloan, A.E.; Ouyang, G.; McLendon, R.E.; Yu, J.S.; Rich, J.N.; Bao, S. The zinc finger transcription factor ZFX is required for maintaining the tumorigenic potential of glioblastoma stem cells. Stem Cells 2014, 32, 2033-2047. [CrossRef]

22. Tatard, V.M.; Xiang, C.; Biegel, J.A.; Dahmane, N. ZNF238 is expressed in postmitotic brain cells and inhibits brain tumor growth. Cancer Res. 2010, 70, 1236-1246. [CrossRef]

23. Bosnyak, E.; Michelhaugh, S.K.; Klinger, N.V.; Kamson, D.O.; Barger, G.R.; Mittal, S.; Juhasz, C. Prognostic Molecular and Imaging Biomarkers in Primary Glioblastoma. Clin. Nucl. Med. 2017, 42, 341-347. [CrossRef] [PubMed]

24. Marosvari, D.; Nagy, N.; Kriston, C.; Deak, B.; Hajdu, M.; Bodor, C.; Csala, I.; Bago, A.G.; Szallasi, Z.; Sebestyen, A.; et al. Discrepancy Between Low Levels of mTOR Activity and High Levels of P-S6 in Primary Central Nervous System Lymphoma May Be Explained by PAS Domain-Containing Serine/Threonine-Protein Kinase-Mediated Phosphorylation. J. Neuropathol. Exp. Neurol. 2018, 77, 268-273. [CrossRef] [PubMed]

25. Cancer Genome Atlas Research Network. Comprehensive genomic characterization defines human glioblastoma genes and core pathways. Nature 2008, 455, 1061-1068. [CrossRef]

26. Huntley, S.; Baggott, D.M.; Hamilton, A.T.; Tran-Gyamfi, M.; Yang, S.; Kim, J.; Gordon, L.; Branscomb, E.; Stubbs, L. A comprehensive catalog of human KRAB-associated zinc finger genes: Insights into the evolutionary history of a large family of transcriptional repressors. Genome Res. 2006, 16, 669-677. [CrossRef]

27. Imbeault, M.; Helleboid, P.Y.; Trono, D. KRAB zinc-finger proteins contribute to the evolution of gene regulatory networks. Nature 2017, 543, 550-554. [CrossRef] [PubMed]

28. Nowick, K.; Fields, C.; Gernat, T.; Caetano-Anolles, D.; Kholina, N.; Stubbs, L. Gain, loss and divergence in primate zinc-finger genes: A rich resource for evolution of gene regulatory differences between species. PLoS ONE 2011, 6, e21553. [CrossRef]

29. Farmiloe, G.; Lodewijk, G.A.; Robben, S.F.; van Bree, E.J.; Jacobs, F.M.J. Widespread correlation of KRAB zinc finger protein binding with brain-developmental gene expression patterns. Philos. Trans. R. Soc. B 2020, 375, 20190333. [CrossRef]

30. Zhang, J.; Luo, J.; Jiang, H.; Xie, T.; Zheng, J.; Tian, Y.; Li, R.; Wang, B.; Lin, J.; Xu, A.; et al. The Tumor Suppressor Role of Zinc Finger Protein 671 (ZNF671) in Multiple Tumors Based on Cancer Single-Cell Sequencing. Front. Oncol. 2019, 9, 1214. [CrossRef]

31. Uhlen, M.; Zhang, C.; Lee, S.; Sjostedt, E.; Fagerberg, L.; Bidkhori, G.; Benfeitas, R.; Arif, M.; Liu, Z.; Edfors, F.; et al. A pathology atlas of the human cancer transcriptome. Science 2017, 357, eaan2507. [CrossRef]

32. Guan, C.; He, L.; Chang, Z.; Gu, X.; Liang, J.; Liu, R. ZNF774 is a potent suppressor of hepatocarcinogenesis through dampening the NOTCH2 signaling. Oncogene 2020, 39, 1665-1680. [CrossRef]

33. Wu, X.; Zhang, X.; Yu, L.; Zhang, C.; Ye, L.; Ren, D.; Li, Y.; Sun, X.; Yu, L.; Ouyang, Y.; et al. Zinc finger protein 367 promotes metastasis by inhibiting the Hippo pathway in breast cancer. Oncogene 2020, 39, 2568-2582. [CrossRef] [PubMed]

34. Murat, A.; Migliavacca, E.; Hussain, S.F.; Heimberger, A.B.; Desbaillets, I.; Hamou, M.F.; Ruegg, C.; Stupp, R.; Delorenzi, M.; Hegi, M.E. Modulation of angiogenic and inflammatory response in glioblastoma by hypoxia. PLoS ONE 2009, 4, e5947. [CrossRef] [PubMed] 
35. Pang, F.; Zha, R.; Zhao, Y.; Wang, Q.; Chen, D.; Zhang, Z.; Chen, T.; Yao, M.; Gu, J.; He, X. MiR-525-3p enhances the migration and invasion of liver cancer cells by downregulating ZNF395. PLoS ONE 2014, 9, e90867. [CrossRef] [PubMed]

36. Nakada, M.; Kita, D.; Watanabe, T.; Hayashi, Y.; Teng, L.; Pyko, I.V.; Hamada, J. Aberrant signaling pathways in glioma. Cancers 2011, 3, 3242-3278. [CrossRef] [PubMed]

37. De Luca, A.; Maiello, M.R.; D'Alessio, A.; Pergameno, M.; Normanno, N. The RAS/RAF/MEK/ERK and the PI3K/AKT signalling pathways: Role in cancer pathogenesis and implications for therapeutic approaches. Expert Opin. Ther. Targets 2012, 16, 17-27. [CrossRef] [PubMed]

38. Hemmings, B.A.; Restuccia, D.F. PI3K-PKB/Akt pathway. Cold Spring Harb. Perspect. Biol. 2012, 4, a011189. [CrossRef] [PubMed]

39. Alqurashi, N.; Hashimi, S.M.; Wei, M.Q. Chemical Inhibitors and microRNAs (miRNA) Targeting the Mammalian Target of Rapamycin (mTOR) Pathway: Potential for Novel Anticancer Therapeutics. Int. J. Mol. Sci. 2013, 14, 3874-3900. [CrossRef]

40. Park, H.K.; Hong, J.H.; Oh, Y.T.; Kim, S.S.; Yin, J.; Lee, A.J.; Chae, Y.C.; Kim, J.H.; Park, S.H.; Park, C.K.; et al. Interplay between TRAP1 and Sirtuin-3 Modulates Mitochondrial Respiration and Oxidative Stress to Maintain Stemness of Glioma Stem Cells. Cancer Res. 2019, 79, 1369-1382. [CrossRef]

41. Szarvas, T.; Csizmarik, A.; Szucs, M.; Nyiradi, P. Molecular subtypes and perspectives of targeted therapies in prostate cancer. Orv. Hetil. 2019, 7, 252-263. [CrossRef]

42. Bottyan, K.; Kemeny, L.; Csoma, Z.R. Successful treatment of facial angiofibromas with local sirolimus in childhood in Bourneville-Pringle disease. Orv. Hetil. 2019, 13, 516-520.

43. Li, X.; Wu, C.; Chen, N.; Gu, H.; Yen, A.; Cao, L.; Wang, E.; Wang, L. PI3K/Akt/mTOR signaling pathway and targeted therapy for glioblastoma. Oncotarget 2016, 7, 33440-33450. [CrossRef] [PubMed]

44. Zhao, H.F.; Wang, J.; Shao, W.; Wu, C.P.; Chen, Z.P.; To, S.T.; Li, W.P. Recent advances in the use of PI3K inhibitors for glioblastoma multiforme: Current preclinical and clinical development. Mol. Cancer 2017, 16, 100. [CrossRef] [PubMed]

45. Juric, V.; Murphy, B. Cyclin-dependent kinase inhibitors in brain cancer: Current state and future directions. Cancer Drug Resist. 2020, 3, 48-62. [CrossRef]

46. Jean-Quartier, C.; Jeanquartier, F.; Holzinger, A. Open Data for Differential Network Analysis in Glioma. Int. J. Mol. Sci. 2020, 21, 547. [CrossRef]

47. Wang, L.; Wei, B.; Hu, G.; Wang, L.; Bi, M.; Sun, Z.; Jin, Y. Screening of differentially expressed genes associated with human glioblastoma and functional analysis using a DNA microarray. Mol. Med. Rep. 2015, 12, 1991-1996. [CrossRef]

48. Huang, H.; Hara, A.; Homma, T.; Yonekawa, Y.; Ohgaki, H. Altered expression of immune defense genes in pilocytic astrocytomas. J. Neuropathol. Exp. Neurol. 2005, 64, 891-901. [CrossRef]

49. Zagzag, D.; Salnikow, K.; Chiriboga, L.; Yee, H.; Lan, L.; Ali, M.A.; Garcia, R.; Demaria, S.; Newcomb, E.W. Downregulation of major histocompatibility complex antigens in invading glioma cells: Stealth invasion of the brain. Lab. Investig. 2005, 85, 328-341. [CrossRef]

50. Caffery, B.; Lee, J.S.; Alexander-Bryant, A.A. Vectors for Glioblastoma Gene Therapy: Viral \& Non-Viral Delivery Strategies. Nanomaterials 2019, 9, 105. [CrossRef]

51. Lang, F.F.; Bruner, J.M.; Fuller, G.N.; Aldape, K.; Prados, M.D.; Chang, S.; Berger, M.S.; McDermott, M.W.; Kunwar, S.M.; Junck, L.R.; et al. Phase I trial of adenovirus-mediated p53 gene therapy for recurrent glioma: Biological and clinical results. J. Clin. Oncol. 2003, 21, 2508-2518. [CrossRef]

52. Hong, Y.K.; Joe, Y.A.; Yang, Y.J.; Lee, K.S.; Son, B.C.; Jeun, S.S.; Chung, D.S.; Cho, K.K.; Park, C.K.; Kim, M.C.; et al. Potentials and limitations of adenovirus-p53 gene therapy for brain tumors. J. Korean Med. Sci. 2000, 15, 315-322. [CrossRef]

53. Okura, H.; Smith, C.A.; Rutka, J.T. Gene therapy for malignant glioma. Mol. Cell. Ther. 2014, 2, 21. [CrossRef] [PubMed]

54. Mees, C.; Nemunaitis, J.; Senzer, N. Transcription factors: Their potential as targets for an individualized therapeutic approach to cancer. Cancer Gene Ther. 2009, 16, 103-112. [CrossRef] [PubMed]

55. Hawrylycz, M.J.; Lein, E.S.; Guillozet-Bongaarts, A.L.; Shen, E.H.; Ng, L.; Miller, J.A.; van de Lagemaat, L.N.; Smith, K.A.; Ebbert, A.; Riley, Z.L.; et al. An anatomically comprehensive atlas of the adult human brain transcriptome. Nature 2012, 489, 391-399. [CrossRef] [PubMed] 
56. Wesseling, P.; Capper, D. WHO 2016 Classification of gliomas. Neuropathol. Appl. Neurobiol. 2018, 44, 139-150. [CrossRef] [PubMed]

57. Ceccarelli, M.; Barthel, F.P.; Malta, T.M.; Sabedot, T.S.; Salama, S.R.; Murray, B.A.; Morozova, O.; Newton, Y.; Radenbaugh, A.; Pagnotta, S.M.; et al. Molecular Profiling Reveals Biologically Discrete Subsets and Pathways of Progression in Diffuse Glioma. Cell 2016, 164, 550-563. [CrossRef]

58. Goldman, M.; Craft, B.; Hastie, M.; Repečka, K.; McDade, F.; Kamath, A.; Banerjee, A.; Luo, Y.; Rogers, D.; Brooks, A.N.; et al. The UCSC Xena platform for public and private cancer genomics data visualization and interpretation. BioRxiv 2019, 326470. [CrossRef]

59. Sarkozy, M.; Zvara, A.; Gyemant, N.; Fekete, V.; Kocsis, G.F.; Pipis, J.; Szucs, G.; Csonka, C.; Puskas, L.G.; Ferdinandy, P.; et al. Metabolic syndrome influences cardiac gene expression pattern at the transcript level in male ZDF rats. Cardiovasc. Diabetol. 2013, 12, 16. [CrossRef]

60. Kauffmann, A.; Gentleman, R.; Huber, W. arrayQualityMetrics-A bioconductor package for quality assessment of microarray data. Bioinformatics 2009, 25, 415-416. [CrossRef]

61. Benjamini, Y.; Drai, D.; Elmer, G.; Kafkafi, N.; Golani, I. Controlling the false discovery rate in behavior genetics research. Behav. Brain Res. 2001, 125, 279-284. [CrossRef]

62. Draghici, S.; Khatri, P.; Tarca, A.L.; Amin, K.; Done, A.; Voichita, C.; Georgescu, C.; Romero, R. A systems biology approach for pathway level analysis. Genome Res. 2007, 17, 1537-1545. [CrossRef]

(C) 2020 by the authors. Licensee MDPI, Basel, Switzerland. This article is an open access article distributed under the terms and conditions of the Creative Commons Attribution (CC BY) license (http://creativecommons.org/licenses/by/4.0/). 